
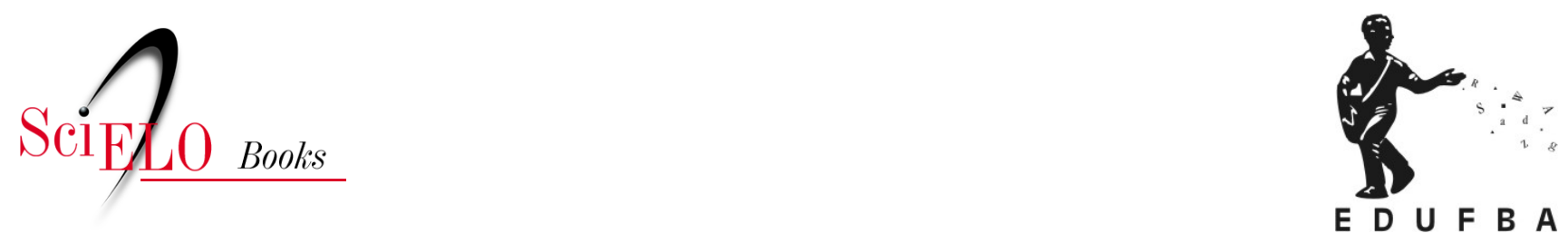

\title{
Pensar por montagens
}

\author{
Paola Berenstein Jacques
}

JACQUES, P.B. Pensar por montagens. In: JACQUES, P.B., and PEREIRA, M.S., comps. Nebulosas do pensamento urbanístico: tomo I- modos de pensar [online]. Salvador: EDUFBA, 2018, pp. 206-234. ISBN 978-85-232-2032-7. https://doi.org/10.7476/9788523220327.0009.

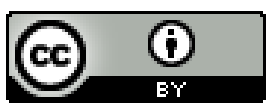

All the contents of this work, except where otherwise noted, is licensed under a Creative Commons Attribution 4.0 International license.

Todo o conteúdo deste trabalho, exceto quando houver ressalva, é publicado sob a licença Creative Commons Atribição 4.0. 
PENSA R PO R 


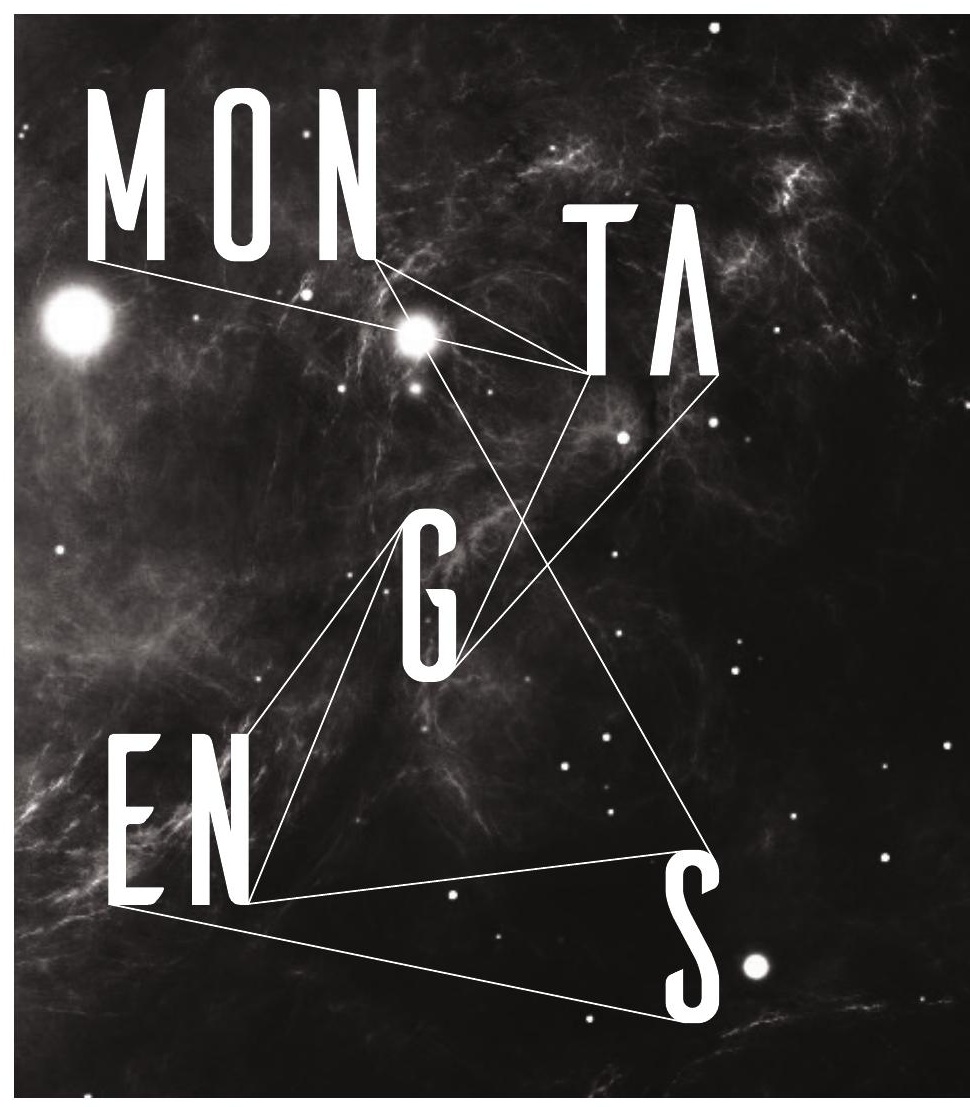




$$
\begin{aligned}
& \text { PENSAR } \\
& \text { P O } \mathrm{B} \\
& \text { M O N T A G E N S } \\
& P \wedge O<\Lambda \\
& \text { B E RE NSTE I N } \\
& J A C Q U E S
\end{aligned}
$$


A montagem será precisamente uma das respostas fundamentais ao problema de construção da historicidade. Porque não está orientada simplesmente, a montagem escapa às teleologias, torna visíveis as sobrevivências, os anacronismos, os encontros de temporalidades contraditórias que afetam cada objeto, cada acontecimento, cada pessoa, cada gesto. Então, o historiador renuncia a contar 'uma história' mas, ao fazê-lo, consegue mostrar que a história não é senão todas as complexidades do tempo, todos os estratos da arqueologia, todos os pontilhados do destino.

(DIDI-HUBERMAN, 2012, p. 212)

\section{SOBREVIVÊNCIAS}

by Warburg, historiador da arte que nunca se restringiu ao campo mais estrito da arte e sempre dialogou com outros campos - em particular, com a cultura, a antropologia e a arqueologia -, procurava o que estava escondido ou parecia não ser merecedor de atenção pela maioria dos historiadores, como pequenos fragmentos, pedaços ou detalhes - como dito em sua célebre frase: "o bom Deus se esconde nos detalhes" - e recorreu à montagem como "forma de conhecimento"2 ou como "imagem de pensamento" - Denkbild, como diria Walter Benjamin -, ${ }^{3}$ 
em particular, no seu famoso Atlas Mnemosyne (ou Mnemosine, deusa da memória na mitologia grega), que ele "montou" em sua biblioteca - Kulturwissenschaftliche Bibliothek, a biblioteca para a ciência da cultura - entre 1924 e 1929. O Atlas de Warburg era visual, composto basicamente por imagens e detalhes de imagens ou recortes variados, sempre intercambiáveis. Um Atlas, esse titã, na mitologia grega, condenado por Zeus a carregar os céus nos ombros, já pressupõe um tipo de montagem visual, uma "forma visual de conhecimento" segundo Georges Didi-Huberman (2010). ${ }^{4}$

O Atlas Mnemosyne é composto por um conjunto de grandes painéis móveis - painéis simples, de madeira, cobertos de preto, medindo aproximadamente 2 × 1,5 metros cada - que ficavam expostos na entrada da sala de leitura de sua biblioteca em Hamburgo, onde a palavra "Mnemosyne" foi gravada e todos os livros eram dispostos a partir da "lei da boa vizinhança", ${ }^{5}$ onde Warburg compôs e expôs suas montagens. Essas montagens eram realizadas a partir de um arquivo com centenas - talvez milhares, só nos painéis da última versão são quase mil imagens - de imagens bastante heterogêneas: fotografias de obras de arte, de detalhes de obras, imagens cosmográficas, cartográficas, mapas, desenhos e esquemas variados, recortes de jornais e de revistas do momento em que o painel foi montado (1929, última versão, ano de sua morte), entre outros. Warburg usava os painéis em suas aulas, palestras, exposições e apresentações. Os painéis móveis eram constantemente montados, desmontados e remontados em função do andamento de seus estudos e, em seguida, fotografados. A última versão do Atlas foi composta de dezenas de painéis de madeira. ${ }^{6}$ Trata-se de um tipo de "testamento metodológico" de Warburg, que até hoje parece assombrar as formas mais tradicionais e hegemônicas de se pensar a história - em particular, a história da arte -, ao questionar, sobretudo, as relações mais simplistas entre memória e história. ${ }^{7}$

A questão principal de Warburg em seu atlas de imagens (Bilderatlas), como na grande maioria de seus trabalhos, era buscar aquilo que ele chamou de Nachleben der Antike, um tipo de sobrevivência - um tipo de "vida" que ressurge em outra época, algo que permanece vivo, principalmente na memória, e "assombra" épocas posteriores - da 210 Antiguidade, no Renascimento. Tratava-se também da sobrevivência 
de uma civilização, de uma cultura pagã (Nachleben des Heidentums), o que já o levava a um atravessamento do campo específico da arte para o campo da antropologia. ${ }^{8}$ Warburg também realizou trabalhos de campo com viés etnográfico, ${ }^{9}$ sempre no limiar entre diferentes campos disciplinares, sobretudo ao se confrontar com o formalismo esteticista e com estudos meramente estilísticos, do chamado "método estilístico-formal" ainda dominante na história da arte do século XIX ${ }^{10}$ no campo da arte, tensionando também os limites da própria história da arte, buscando sempre trabalhar através ou além - no limiar dos campos disciplinares estabelecidos -, cruzando, assim, diferentes campos de conhecimento, transgredindo os limites tradicionais das disciplinas, como em seu atlas: "Mnemosyne junta o que as fronteiras disciplinares tinham costume de separar". (DIDI-HUBERMAN, 2011a, p. 78)

Nachleben, aqui traduzido por "sobrevivência" - em alguns textos, encontra-se "vida póstuma" ou "sobrevida" -, seria um processo de transmissão, de transformação, de recepção e também de como a memória, sobretudo a involuntária (proustiana) ou inconsciente (freudiana), opera nesses processos. Trata-se de uma forma de presença ou de "herança", como dizia Ernst Bloch (Erbschaft dieser Zeit), de um tempo que ainda sobrevive, mesmo que em breves lampejos mnemônicos, em outro tempo. Um tipo de anacronismo pautado na questão da memória, ${ }^{11}$ da memória social, cultural, mas também, e sobretudo, da memória involuntária, que pode ser bem exemplificada pela célebre passagem da madeleine do livro de Proust, Em busca do tempo perdido - que foi traduzido para o alemão por Walter Benjamin -, quando o narrador, ao provar um simples pedaço de madeleine, um pequeno bolo francês, molhado no chá, faz emergir a memória de sua infância a partir do paladar. A memória involuntária, como nos sonhos - e também, claro, no seu despertar -, opera por montagens, criando nexos inesperados, de forma não linear, anacrônica e fragmentária.

O Atlas de Warburg (2009, p. 132) é um titânico "sistema mneumotécnico", para usar a expressão de Agamben, que escreveu: "a 'ciência sem nome' buscada por Warburg é, como registra uma anotação de 1929, uma 'iconologia do intervalo'”. Warburg ficou conhecido, em particular, a partir dos trabalhos de Panofsky, como o criador - contra uma iconografia formalista e estetizante - da iconologia, "ciência" que 
vai além das formas da iconografia tradicional ao incorporar também os significados das imagens. No entanto, a "iconologia do intervalo" proposta por Warburg é bem mais complexa que a proposta de iconologia defendida por Panofsky. O foco de Warburg estaria menos em cada imagem em si e mais no próprio intervalo entre elas, no vazio entre as imagens, nas suas possíveis relações, não estabelecidas a priori, mas que emergem no próprio exercício da montagem. Seu interesse pelas imagens residia justamente no seu caráter lacunar, híbrido, falho, impuro, incompleto, intermediário, aberto. Aby Warburg buscava uma concepção de história sempre aberta aos "possíveis ainda não dados", que acolhesse as impurezas, as descontinuidades, as lacunas e os anacronismos. A definição mais interessante para seu atlas de imagens da memória é do próprio Warburg - a partir da noção de Nachleben, que também pode ser vista como uma vida fantasmática das imagens -, ao explicar que o que ele buscava fazer era um tipo de "história de fantasmas para gente grande". ${ }^{12}$

Contra toda pureza epistêmica, o Atlas introduz no saber a dimensão sensível, o diverso, o caráter lacunar de cada imagem. Contra toda pureza estética, ele introduz o múltiplo, o diverso, o caráter híbrido de toda montagem [...] Ele é uma ferramenta, não de esgotamento lógico de possibilidades dadas, mas da inesgotável abertura aos possíveis ainda não dados. (DIDIHUBERMAN, 2011a, p. 13, grifo e tradução nossos)

A "forma de pensar"13 e a concepção da história (ele considerava os historiadores e os sábios "sismógrafos hipersensíveis") de Warburg operam por montagens e imagens consteladas de detalhes (vestígios, reminiscências, gestos). $\mathrm{O}$ processo de montagem, desmontagem e remontagem compõe diferentes constelações. Trata-se de uma forma complexa, de "caráter híbrido", de produzir conhecimento "contra toda pureza epistêmica”, uma compreensão sinóptica que cruza diferentes campos e disciplinas e que não pode ser engessada como uma simples metodologia operacional. $\mathrm{O}$ importante não seria qualquer tipo de resultado final fixo, mas sim o próprio processo aberto, uma renúncia do fixar. A partir dos diferentes intervalos - entre as diferentes remontagens de um mesmo painel, entre as montagens de diferentes painéis 212 e também entre as imagens de cada montagem -, podem surgir outros 
nexos, a partir de associações, choques ou tensões entre as imagens, podem emergir relações inesperadas, outras constelações imprevistas, provocando uma série de deslocamentos, inversões, rupturas, descontinuidades, emergências, anacronismos e sobrevivências. ${ }^{14}$

\section{Montagens}

Método deste trabalho: montagem literária. Não tenho nada a dizer. Somente a mostrar. Não surrupiarei coisas valiosas, nem me apropriarei de formulações espirituosas. Porém, os farrapos, os resíduos: não quero inventariá-los, e sim fazer-lhes justiça da única maneira possível: utilizando-os. (BENJAMIN, 2009, p. 502)

Esse curto fragmento do livro das Passagens resume bem o processo deste gigantesco trabalho sobre a cidade de Paris feito por Walter Benjamin, explicitando o tipo de montagem que Benjamin executava não só nesse trabalho sobre Paris, que, como se sabe, ficou inacabado com sua morte prematura, mas também em outras publicações, sobretudo em Einbahnstraße. Traduzido como Rua de mão única e dedicado a Asja Lacis, ${ }^{15}$ o livro de 1928 é um bom exemplo concluso do exercício benjaminiano de montagem, tanto literária quanto editorial, publicado com uma bela fotomontagem de Sascha Stone na capa, da cidade da infância do autor, Berlim. Segundo o biógrafo de Benjamin, Bernd Witte (2017, p. 71): "Esse livro, o único não acadêmico que Benjamin chegou a publicar em vida, tornou-se uma das obras mais significativas da literatura de vanguarda em língua alemã nos anos 1920, e isso se deu por sua forma gráfica e seu design externo".

A montagem literária estava também diretamente relacionada com as narrativas de experiências urbanas dos surrealistas que tanto fascinaram Benjamin, provocando aquilo que ele chamou de "iluminação profana”; em particular, os livros que partem de deambulações pelas ruas e espaços públicos de Paris - verdadeiras montagens, tanto do ponto de vista literário ("escrita automática") como editorial (tipografia, inserção de anúncios, fotografias etc.) - Le paysan de Paris, ou $\mathrm{O}$ camponês de Paris, de 1926, de Louis Aragon, e Nadja (1928), de André Breton. A leitura do livro de Aragon, que provocou taquicardia ${ }^{16}$ em Benjamin, 
foi determinante para a escolha da forma literária e editorial para a publicação de Rua de mão única, sem dúvida alguma sua publicação mais surrealista, montada como uma deambulação por uma rua de Berlim. Como comenta Jeanne Marie Gagnebin (2017, p. 22):

Rua de mão única se transforma numa sequência de 61 textos, curtos ou mais longos, que podem muito bem mimetizar os dois lados de uma rua berlinense [...] Bernd Witte vê assim correspondências entre o número 1 ('Posto de Gasolina') e o número 31 ('Loja de Antiquidades') como os dois lados opostos da mesma rua, um emblema da técnica moderna de um lado, um acúmulo de coisas antigas do outro.

Nos três livros - O camponês de Paris, Nadja e Rua de mão única -, a experiência urbana da cidade moderna - em particular, da rápida transformação das antigas cidades europeias a partir dos grandes projetos modernizadores - é a principal protagonista.

Gagnebin (2017, p. 23) nos mostra também uma analogia em Rua de mão única, "entre esse caminhar (na cidade moderna) que esbarra em obstáculos e entre a escritura que o descreve”. Ela mostra também que há uma mudança na própria forma de escrever do autor:

Todos os críticos desse livro, a começar por Bloch, Adorno e Kracauer, seus primeiros resenhistas, realçam nele uma mudança literária essencial. Benjamin escreve por fragmentos, ou melhor em Denkbilder, 'imagens de pensamento', não mais seguindo um estilo argumentativo dedutivo e linear. (GAGNEBIN, 2017, p. 33)

Benjamin usa a montagem como procedimento literário, o que também não deixa de ser uma forma de narração da própria experiência das cidades modernas, de sua experiência de Berlim - mas também de Moscou, Riga, Nápoles e Paris - em Rua de mão única e de Paris no livro das Passagens.

A leitura do livro de Aragon, em particular, o capítulo escrito em 1924 sobre "A passagem da ópera", foi crucial também para Benjamin 214 encontrar o tema central - as passagens parisienses - de seu trabalho 
sobre Paris como capital do século XIX, como capital da própria modernidade. A passagem da ópera, tema desse capítulo de Aragon, era um lugar de encontro dos surrealistas e foi demolida na continuação da reforma haussmaniana da cidade, em 1925. As passagens, gloriosas no século XIX, já pareciam obsoletas nos anos $1920 .{ }^{17}$ No início do século XX, em menos de 100 anos de existência - a maioria surgiu por volta de 1820 -, elas já pareciam antiquadas, sendo que, no século XIX, elas ainda eram o sonho moderno da época seguinte. Benjamin costumava citar Michelet: "Cada época sonha a seguinte". As passagens naquele momento já eram reminiscências em miniatura desse antigo sonho urbano moderno. ${ }^{18}$ Nelas, diferentes tempos passaram a coexistir e, assim, a linearidade histórica - passado, presente e futuro - foi rompida.

[...] A primeira etapa desse caminho será aplicar à história o princípio da montagem. Isto é: erguer as grandes construções a partir de elementos minúsculos, recortados com clareza e precisão [...] Portanto romper com o naturalismo histórico vulgar. Apreender a construção da história como tal. (BENJAMIN, 2009, p. 503)

O processo de montagem, para Benjamim, era uma outra forma de narrar, de escrever a história - e, assim, propor uma outra teoria da história -, de "erguer as grandes construções (historiográficas) a partir elementos minúsculos, recortados com clareza e precisão”, mas também de narrar a história de uma cidade. Seja na montagem literária, seja na montagem historiográfica ou, ainda, na montagem urbana, associações improváveis proporcionam choques entre ideias diferentes, a partir de diferentes citações ou de diferentes tempos e espaços. As passagens também são "esses elementos minúsculos, recortados com clareza e precisão”, sejam as passagens textuais, citações e recortes de textos variados, que vão de uma ideia para outra; sejam as passagens temporais, de um tempo para outro, de uma época para outra; sejam ainda as passagens arquitetônicas, urbanas, que levam de uma rua para outra, de um espaço urbano para outro. $O$ procedimento da montagem surge, assim, como uma forma de apreender a complexidade da construção da grande cidade moderna, mas também para "apreender a construção da história como tal" - assim, outras 
formas de narração histórica criadas para buscar "romper com o naturalismo histórico vulgar".

A ideia de passagem funcionava, assim, para Benjamin, tanto teórica quanto criticamente, como uma categoria analítica da cidade moderna, da modernidade e da própria história. Ele buscava uma narração histórica polifônica e aberta (inacabada), mostrando as diferentes passagens temporais de uma época para outra ou ainda as diferentes "sobrevivências", retomando o termo usado por Warburg, de uma época em outra. O título Passagens também pode ser visto simplesmente como uma coleção das diversas passagens textuais, os próprios fragmentos selecionados ou catados, as diferentes citações e anotações realizadas por Benjamin, tanto as passagens textuais quanto as passagens de um texto citadas em outro, por vezes repetidas ou atualizadas. Eram sempre os fragmentos, "os farrapos, os resíduos", tanto temporais quanto textuais, que interessavam Benjamin e, como ele insistia, "não bastava inventariá-los, seria preciso utilizá-los”.

Uma fotografia muito conhecida de 1939, feita por Gisèle Freund, mostra Benjamin em atividade na Biblioteca Nacional da França (BNF), em pleno processo de montagem. Podemos vê-lo numa mesa com uma caneta na mão entre várias fichas, copiando referências, citações, escrevendo notas. Benjamin praticava a montagem como um verdadeiro colecionador - a figura do colecionador aparece em várias passagens, assim como a do trapeiro - ou um catador de fragmentos. Colecionava citações, resumos, notas, aforismos, pedaços de textos de campos distintos. Em suma, fragmentos. ${ }^{19}$ Para além da figura emblemática do colecionador, do catador ou do trapeiro, Hannah Arendt formula uma das mais belas descrições de Walter Benjamin, sempre preocupado com a transmissão da experiência passada no presente a partir do uso do que estava escondido, esquecido ou descartado: um "pescador de pérolas". E explica, citando o próprio Benjamin em Rua de mão única, sua forma de usar as citações: "As citações, no meu trabalho, são como os ladrões de grandes caminhos que aparecem do nada e despojam o caminhante de suas convicções”. O pescador de 216 pérolas seria esse colecionador de citações, de "pérolas e corais", essa 
"figura aparentemente bizarra do colecionador que vai recolher nos entulhos do passado seus fragmentos e suas peças”. Em sua coleção, "podemos sem dificuldade encontrar ao lado de um poema de amor ignorado do século 18, a última notícia do jornal”, diz ainda Hannah Arendt (2007, p. 100).

A prática dessas montagens seria, assim, uma forma de utilização daquilo que sobrou, que já parece obsoleto, uma forma de usar os restos, farrapos e resíduos da história através de uma remontagem de antigos fragmentos. Seria, assim, um processo de mistura temporal, mas também de narrativas e narradores, de tempos e narrações heterogêneas, um processo de montagem que formaria também uma série de polifonias. ${ }^{20} \mathrm{Um}$ procedimento crítico, uma desmontagem, a partir da justaposição de fragmentos distintos, a partir de suas diferenças. A montagem aparece, então, como forma de conhecimento histórico no momento em que ela também caracteriza o objeto desse conhecimento: o historiador cata e monta com os fragmentos que sobram porque estes têm a capacidade tanto de desmontar a história "oficial" ou "hegemônica" do presente, quanto de remontar outros tempos heterogêneos.

Há de se exigir do pesquisador que ele abandone uma atitude serena, a típica atitude contemplativa, ao se colocar diante seu objeto, para tomar assim consciência da constelação crítica em que esse preciso fragmento do passado se situa precisamente nesse presente. ${ }^{21}$ (BENJAMIN, 2009, p. 71, grifo e tradução nossos)

Walter Benjamin recorreu à ideia de constelação algumas vezes para explicar sua própria forma de pensar por montagens de fragmentos e, em particular, sua forma de pensar e tensionar o próprio campo da história. Trata-se de um complexo jogo de forças entre passado e presente e também de propostas de futuro, ${ }^{22}$ entre o "ocorrido", o "agora" e o porvir, através de montagens sinópticas de tempos heterogêneos, forças do passado ressurgem no presente indicando futuros, forças que sobrevivem para além de sua cristalização, como relâmpagos, lampejos, memórias involuntárias. Trata-se de uma montagem de tempos heterogêneos, uma coexistência de tempos distintos, uma apresentação 
sinóptica de diferenças. Um tipo de conhecimento específico e complexo é operado pela prática, trabalho ou jogo da montagem, um exercício que não busca qualquer unidade e pretende mostrar a própria complexidade ao acentuar diferenças e ao misturar, colocando lado a lado, numa mesma superfície, como no Atlas de Warburg ou no livro das Passagens de Benjamin, diferentes tipos de fragmentos, documentos, textos ou imagens, ou detalhes de diferentes tempos e campos do conhecimento e, a partir do choque entre suas diferenças, nos fazem compreender outros nexos possíveis, não mais baseados em semelhanças, mas sim na própria diversidade e heterogeneidade.

O complexo processo de montagem-desmontagem-remontagem pode ser pensado também como uma forma de ação política, por ser também, sempre, uma forma de desmontagem do status quo, das certezas mais consolidadas, como nos propõe Georges DidiHuberman (2007, p. 1): "A montagem seria às formas o que a política seria aos atos: é preciso juntar dois significados da desmontagem que são o excesso das energias e a estratégia dos lugares, a loucura da transgressão e a sabedoria da posição".

Benjamin e Warburg pensavam por montagens, por diferenças, por deslocações, por decomposições e outras disposições, para buscar apreender, de forma caleidoscópica - forma privilegiada da modernidade - uma certa "desordem" ou "desencantamento" do mundo, decorrente tanto da experiência da guerra, quanto da própria experiência cotidiana da grande cidade moderna em impetuosa transformação, sobretudo a partir dos violentos processos de modernizações urbanas, como as reformas do Barão Haussman em Paris. ${ }^{23}$ Esse moderno pensar por montagens buscava formas mais complexas de ver, apreender a realidade, como aquela oferecida pelo caleidoscópio. ${ }^{24}$

O pensamento por montagens de tempos heterogêneos ou anacrônicos torna a própria noção de tempo bem mais complexa e menos linear, o que permite pensar também outras formas de narração. Um tempo saturado de "agoras" que se encontram com "outroras” em relâmpagos ou breves lampejos, indicando possibilidades futuras. ${ }^{25}$ Trata-se de uma desmontagem também do 218 historicismo, das formas de se pensar e narrar a história baseadas 
numa simples continuidade ou linearidade histórica como mera sucessão de tempos homogêneos.

O conhecimento pela montagem foi uma resposta das vanguardas modernas ${ }^{26}$ aos excessos da própria modernidade, de sua cientificidade "positivista", da ideia de progresso inelutável e acrítico, mas também uma resposta contra os diferentes fechamentos metodológicos funcionalistas e contra os formalismos estetizantes, ambos ainda dominantes em diferentes campos disciplinares. $O$ pensamento pela montagem propõe uma forma aberta de conhecimento por relações, por associações inusitadas de ideias, por "afinidades eletivas", como diria Goethe e Benjamin, ou pela "lei da boa vizinhança", como na biblioteca de Warburg. Um tipo de conhecimento transversal que atravessa campos distintos e explora seus limiares, explodindo seus limites ou fronteiras. Uma forma de conhecimento processual construído pela própria prática, na ação mesma de montar/desmontar/ remontar, que admite o acaso - o "acaso objetivo" dos surrealistas -, uma espécie de jogo de cartas de tarô, de búzios ou de dados, como em Mallarmé. Uma forma de pensar em movimento, que atua pelas diferenças, pelas multiplicidades, um pensamento em transformação permanente, que recusa qualquer síntese conclusiva assumindo a incompletude como princípio. Essa forma de pensar por montagens, desses "outros modernos" ou "modernos críticos", ${ }^{27}$ pode ser atualizada, desde que seja repensada também a questão - ou o tabu, no campo da história - do anacronismo.

\section{Anacronismos}

O anacronismo, desde logo, poderia não ser reduzido ao que todo historiador patenteado considera espontaneamente um horrivel pecado. Ele poderia ser pensado como um momento, como uma pulsação rítmica do método, fosse ele seu momento de síncope, fosse paradoxal, perigoso como o é necessariamente todo risco. (DIDI-HUBERMAN, 2015, p. 28)

A recusa do anacronismo costuma ser um consenso entre historiadores. A regra é não projetar o presente no passado, mas como podemos 
considerar os diferentes tempos que coexistem em cada época e, em particular, as sobrevivências, para falar como Warburg, de uma determinada época que emerge em outras distintas, provocando um choque entre tempos heterogêneos? Não seria possível pensar por montagens sem "correr o risco" do anacronismo, ainda visto por muitos historiadores como esse enorme "pecado capital" a ser evitado ou "o diabo da história", como se refere Georges Didi-Huberman, ao propor o uso do anacronismo de imagens - pensando a imagem como conceito ou gesto, e não somente como suporte iconográfico como fundamental para o campo da história da arte. Didi-Huberman (2015, p. 42) insiste:

O anacronismo é necessário, o anacronismo é fecundo, quando o passado se revela insuficiente, até mesmo constitua um obstáculo à sua compreensão [...] É provável que não haja história interessante senão na montagem, no jogo rítmico, na contradança das cronologias e dos anacronismos.

Jacques Rancière (2011, p. 46) também retoma a questão no texto "O conceito de anacronismo e a verdade do historiador", em que escreve: "É a ideia mesma de anacronismo como erro quanto ao tempo que deve ser desconstruída”. De que forma podemos, então, ousar o risco do anacronismo para tentar, seguindo ainda Didi-Huberman, tornar mais complexa a narração histórica "na contradança das cronologias e dos anacronismos”, ou seja, levando em consideração toda a complexidade temporal, em particular, através da prática de montagens de tempos heterogêneos?

Jamais se dirá suficientemente a que ponto o medo do anacronismo é bloqueador [...] a audácia de ser historiador, o que equivale, talvez, a assumir o risco do anacronismo (ou pelo menos, de certa dose de anacronismo), com a condição de que seja com inteiro conhecimento de causa e escolhendo-lhe as modalidades. (LORAUX, 1992, p. 57)

A aceitação de uma "prática controlada" do anacronismo, conforme nos indica Nicole Loraux em seu texto "Elogio do anacronismo", ${ }^{28}$ 220 não pressupõe nem uma recusa do eucronismo - compreensão de 
um mesmo tempo - nem a prática de um anacronismo vulgar projeção forçada de um tempo no outro. Trata-se de uma proposta de considerarmos a complexidade de tempos, através das sobrevivências, das emergências de outros tempos, das reminiscências, dos excessos, das sobras e dos restos de tempos distintos que sobrevivem ou ganham uma sobrevida em outros tempos, ou seja, que vivem além de seu próprio tempo, ou ainda através daquilo que se mantém vivo na memória e emerge quando menos se espera. A memória involuntária, como propõe Marcel Proust, é sempre anacrônica, assim como são os sonhos e o momento do despertar. Memórias, sem ser uma rememoração forçada, e sonhos, levando em consideração o despertar, são montagens de tempos e espaços distintos, uma mistura de tempos heterogêneos que poderíamos chamar de heterocronias. Pensar por montagens seria atentar, respeitar ou, ainda, provocar heterocronias. Esse choque de tempos heterogêneos que explicita uma coexistência temporal conflituosa, de temporalidades mais complexas ou mesmo impuras. Trata-se de quebrar a linearidade do tempo positivista, da ideia de progresso e cronologia linear, ao mostrar, por montagens, o inevitável cruzamento, o choque, entre tempos heterogêneos ou, ainda, como diz Jeanne Marie Gagnebin (1999, p. 99), trata-se da "lembrança do passado que desperta no presente o eco de um futuro perdido" e que, portanto, deixa de ser perdido, podendo ser atualizado no presente. $\mathrm{O}$ desafio, portanto, é de incorporar os diferentes tempos - como os das memórias que emergem sem serem solicitadas - nas narrativas históricas para quebrar, fissurar e, assim, ir além das linearidades ou outras simplificações temporais. Como diz Didi-Huberman (2015), "o passado nunca cessa de se reconfigurar”; trata-se de uma construção, permanentemente em disputa.

Em aula inaugural para seus estudantes, Giorgio Agamben buscou responder às seguintes perguntas: "O que é o contemporâneo? De que e de quem somos contemporâneos?", a partir de uma resposta dada por Roland Barthes: "O contemporâneo é o intempestivo". Barthes, por sua vez, seguia Nietzsche em suas "considerações intempestivas". Nas palavras de Agamben (2009): "Nietzsche situa a sua exigência de 'atualidade', a sua 'contemporaneidade' em relação ao presente, numa desconexão e numa dissociação”. E ele completa: 
Pertence verdadeiramente ao seu tempo, é verdadeiramente contemporâneo, aquele que não coincide perfeitamente com este, nem está adequado às suas pretensões e é, portanto, nesse sentido, inatual; mas, exatamente por isso, exatamente através deste deslocamento e deste anacronismo, ele é capaz, mais do que os outros, de perceber e apreender o seu tempo. ${ }^{29}$ (AGAMBEN, 2009, p. 58)

Agamben (2009) demonstra que só seria possível pensar a contemporaneidade a partir, precisamente, da pluralidade de tempos ou, como ele diz "com a condição de cindi-la em mais tempos, de introduzir no tempo uma essencial desomogeneidade". Esse tempo desomogêneo seria próximo do que chamamos de heterocronias, ou seja, montagens de tempos heterogêneos. Agamben explica melhor: uma "interpolação do presente na homogeneidade inerte do tempo linear”. Trata-se, assim, de uma diferente relação com o tempo, não sincrônica e não linear, um tipo de diacronia baseada em dissociações e anacronismos, ou anacronias, como prefere Jacques Rancière (2011), ${ }^{30}$ para tentar retirar a conotação negativa ainda atribuída por vários historiadores ao termo "anacronismo". O mais interessante nessa compreensão do contemporâneo é, por um lado, a relação anacrônica entre diferentes tempos, tornando a história bem mais complexa, e, por outro, as interrupções dissociativas, intempestivas, em sua narração, que fissuram qualquer tipo de cronologia linear.

Compreendam bem que o compromisso que está em questão na contemporaneidade não tem lugar simplesmente no tempo cronológico: é, no tempo cronológico, algo que urge dentro deste e que o transforma. E essa urgência é a intempestividade, o anacronismo que nos permite apreender nosso tempo. (AGAMBEN, 2009, p. 65)

Ao seguir Agamben e Rancière, pode-se afirmar que, para ser verdadeiramente contemporâneo, é preciso ser anacrônico - "aquele que não coincide perfeitamente" com seu próprio tempo - ou ainda ser intempestivo. Para ser contemporâneo, seria preciso deixar que outros tempos emerjam no tempo presente - ou no estudo do passado, 222 para os historiadores, ou do futuro, para os planejadores, arquitetos e 
urbanistas -, escapando da linearidade simplista ao misturar passado, presente e futuro, como nos sonhos, e que, ao despertar destes, seja possível uma melhor compreensão de seu próprio tempo. Trata-se do que Benjamin (2009, p. 504) chamou de imagem - de pensamento que forma uma constelação: "Não se deve dizer que o passado ilumina o presente ou que o presente ilumina o passado. Uma imagem, ao contrário, é aquilo que o Outrora encontra, num relâmpago, o Agora, para formar uma constelação". ${ }^{31}$

Essa coexistência de diferentes tempos está evidente na materialidade da própria cidade, uma vez que no tempo do "agora" estão presentes as sobrevivências do "outrora", sobrevivências, por vezes, de futuros não realizados, mas não de um passado materializado que segue uma cronologia linear. São passados ou futuros que irrompem, emergem no presente e provocam esse choque, uma faísca, de tempos heterogêneos. Em ruínas arquitetônicas, por exemplo, temos resquícios de diversos tempos: de diversos planos de futuro, passados, que acompanham a história do lugar, materializados ou idealizados; de diferentes temporalidades, associadas às práticas urbanas; de planos de futuros no presente, que não param de irromper. $O$ passado, "outrora", permanece um espaço de luta e de tensão no presente, no tempo do "agora", mas também nos sonhos de futuro, mesmo passados. Trata-se de confrontar a linearidade temporal ao explicitar o encontro conflituoso do "outrora" com o "agora", permitindo sobrevivências e tensões de outros tempos.

Pensar por montagens significa pensar pelo choque de tempos heterogêneos, pelas heterocronias - o que Benjamin chamou de "energias revolucionárias do antiquado" e Warburg de "fóssil em movimento" -, quando o "outrora" encontra, "num relâmpago, o "agora”, para formar uma constelação”. São constelações momentâneas cheias de tensões, prenhas de outros tempos. Pensar por montagens, como diz Didi-Huberman na epígrafe deste texto, seria tornar "visíveis as sobrevivências, os anacronismos, os encontros de temporalidades contraditórias que afetam cada objeto, cada acontecimento, cada pessoa, cada gesto". Pensar por montagens no campo da história do pensamento urbanístico também seria pensar por montagens de tempos heterogêneos, "na contradança das cronologias e dos 
anacronismos", tensionando as diferentes narrativas urbanas de seus mais diversos narradores, construtores e praticantes das cidades, de tempos distintos. Seria ainda utilizar os farrapos e resíduos, fragmentos tanto narrativos quanto urbanos, como tensionadores de homogeneidades, totalidades e partilhas hegemônicas, aprendendo com as heterocronias urbanas, já e ainda presentes - sobreviventes, materialmente ou não, mesmo que por vezes apagadas, silenciadas ou esquecidas - em qualquer cidade. 


\section{NOTAS}

1 O presente texto é uma versão reduzida, porém atualizada, do capítulo "Montagem Urbana" no tomo quatro da coleção "Experiências Metodológicas para a compreensão da cidade contemporânea" (publicado pela Edufba em 2015), e constitui um desdobramento do tópico especial "Memória, História, Narração", oferecido na Pós-graduação em Arquitetura e Urbanismo da Faculdade de Arquitetura da Universidade Federal da Bahia (PPG-AU/FAUFBA) em 2016, e do minicurso "Sobrevivências, montagens e anacronismos", oferecido no Programa de PósGraduação em História da Universidade Estadual de Campinas (UNICAMP), Centro Interdisciplinar de Estudos sobre a Cidade (CIEC), e no Programa de Pós-Graduação em Urbanismo (PROURB) da Universidade Federal do Rio de Janeiro (UFRJ), Laboratório de Estudos Urbanos (LeU), em 2017. Agradeço aos participantes do tópico especial e também aos organizadores e participantes das duas versões do minicurso pelos ricos debates.

2 Segundo Georges Didi-Huberman (2009, p. 86, grifo e tradução nossos): "A montagem seria uma forma de conhecimento e um procedimento formal nascidos da guerra, capaz de apreender a 'desordem do mundo'. Ela assinalaria nossa percepção do tempo desde os primeiros conflitos do século XX: ela teria se tornado o método moderno por excelência”.

3 Segundo Georges Didi-Huberman (2017, p. 30, tradução nossa): "A imagem de pensamento é, muitas vezes, algo bem simples ou bem 'menor', até mesmo minúsculo, que nos toca por sua intensidade concreta, imediata e, ao mesmo tempo, sintomática”.

4 "Atlas, finalmente, deu seu nome a uma forma visual de conhecimento: ao conjunto de mapas geográficos, reunidos em um volume, geralmente, em um livro de imagens, cujo destino é oferecer aos nossos olhos, de maneira sistemática ou problemática - inclusive poética, com risco de ser errática, ou ainda surrealista - toda uma multiplicidade de coisas reunidas por afinidades eletivas, como dizia Goethe. [...] No âmbito das artes visuais, o atlas de imagens, Atlas Mnemosyne, composto por Aby Warburg entre 1924 e 1929, que ficou inacabado, constitui para qualquer historiador da arte - e para todo artista hoje - uma obra de referência e um caso absolutamente fascinante". (DIDI-HUBERMAN, 2011a, p. 13, tradução nossa)

5 A heterogênea biblioteca de Warburg foi transferida de Hamburgo para Londres após sua morte, em 1933, durante o regime nazista, se transformando no prestigioso Warburg Institut, associado à Universidade de Londres a partir de 1944. Por sua biblioteca e pelo instituto, passaram intelectuais famosos, considerados seus "seguidores", tais como: Fritz Saxl, Ernst Gombrich, Erwin Panofsky, Frances Yates, Edgar Wind, Ernst Cassirer, Carlo Ginzburg, 
entre vários outros que frequentaram a biblioteca, como Giorgio Agamben. Entretanto, parece que aos seus ditos seguidores - com algumas exceções, como Walter Benjamin, seu contemporâneo, ou, mais tarde, Carlo Ginzburg e Giorgio Agamben - e, talvez, ao próprio Instituto Warburg, tem interessado mais os temas que foram trabalhados por Warburg, em particular, o renascimento italiano e a antiguidade clássica pagã, do que seu método peculiar de trabalho, sua forma de pensamento e de conhecimento - talvez por Warburg ter deixado muitos textos não publicados ou mesmo por seus conhecidos problemas psiquiátricos -, com exceção da forma de ordenação da biblioteca do Instituto, que até hoje preserva na sede em Londres, como na época de Warburg, a "lei da boa vizinhança”, e não uma catalogação biblioteconômica padrão. Sobre a fascinante organização da biblioteca do Instituto Warburg, ver a revista: Common Knowledge, v. 18, n. 1, publicada pela Duke University Press em 2012.

6 A partir das fotografias no arquivo do Instituto Warburg, pode-se ver que as pranchas das montagens foram organizadas por letras e números (de a.C. e de 1 a 79). Algumas foram dispostas no mesmo painel, outras em mais de um painel, outras não têm registro conhecido em fotografias. Essas fotografias dos painéis montados na sala de leitura da biblioteca em Hamburgo, em sua última versão antes da morte de Warburg, em 1929 - os painéis em madeira parecem ter se perdido na mudança da Biblioteca de Warburg para Londres durante a guerra -, foram recentemente publicadas em diferentes línguas: Der Bilderatlas Mnemosyne, em Berlim, pela Akademie Verlag GmbH, em 2003; além de Madri e Paris, respectivamente: Alas Mnemosyne, 2010, e L'Atlas Mnémosyne, 2012.

7 Trata-se de uma "forma de pensar" segundo Leopoldo Waizbort (2015, p. 18, grifo nosso), que organizou recentemente uma antologia em português de textos de Warburg: "Imersas em contextos, as imagens estabelecem relações entre si, arranjam-se em constelações que são variáveis [...] As imagens jamais estão fechadas em si mesmas, como mônadas: elas se abrem para processos de constelação - de que o Atlas Mnemosine seria o exemplo perfeito: imaginando um diálogo de imagens, e de uma forma em que pudessem ser, a cada momento, deslocadas e postas em outras posições, sugerindo novos diálogos com outras imagens, em um processo infindo. [...] Imagens podiam se deslocar no interior de um mesmo painel, ou entre diferentes painéis, assim como painéis podiam ser dispostos em ordenações variadas. Com isso, a possibilidade de associar, constelar, corresponder, tensionar e opor imagens permitiu-lhe uma forma única de conduzir suas discussões, sobretudo em exposições ou palestras. Mas ainda, trata-se de uma forma de pensar: podemos dizer que Warburg pensava com imagens consteladas e montagens, e seu Atlas deveria demonstrar essa possibilidade”.

8 "Sem dúvida, o ponto de vista do qual Warburg considerava os fenômenos humanos coincide singularmente com o das ciências antropológicas. A forma menos infiel de caracterizar sua 'ciência sem nome' seria talvez inseri-la no pro226 jeto de uma futura 'antropologia da cultura ocidental', para a qual convergirão 
a filosofia, a etnologia, a história e a biologia, com vistas a uma 'icologia do intervalo': o Zwischenraum, em que trabalhava sem cessar o tormento simbólico da memória social”. (AGAMBEN, 2009, p. 140)

9 Sobre a conferência de Warburg a respeito do ritual da serpente dos índios norte-americanos, a partir de sua memória do trabalho de campo realizado 30 anos antes, proferida ainda na clínica psiquiátrica, logo antes de sua alta médica, em 1924, ver: Warburg (2011). Sobre o trabalho etnográfico realizado por ele nos Estados Unidos em imagens, base de sua conferência de 1924, ver: Mann e Guidi (1998). Segundo Agamben (2009): "O encontro com a cultura primitiva americana o afastou completamente de uma história da arte como disciplina especializada”.

10 Segundo Agamben (2009, p. 132), Warburg "durante toda sua vida conservou 'franca repulsa' pela 'história de arte estetizante' e pela consideração puramente formal da imagem".

11 Não se trata aqui, obviamente, de um trabalho memorialista sobre a memória voluntária. A questão da memória involuntária não diz respeito a uma "verdade" do que se viveu, como podemos ver no texto de Benjamin (1985, p. 37) sobre Proust: "[...] o importante, para o autor que rememora, não é o que ele viveu, mas o tecido de sua rememoração, o trabalho de Penélope da reminiscência”.

12 "Gespenstergeschicthe für ganz Erwachsene", escreve Warburg em nota datada de 2 de julho de 1929, citado por Didi-Huberman (2002, p. 510), que também cita o enunciado de Nietzsche, por sua vez citado por Warburg (1878): "a interpretação verdadeiramente 'histórica' falaria como um fantasma com fantasmas”.

13 "Ora, só a montagem - como forma de pensamento - permite espacializar essa ‘desterritorialização’ dos objetos de conhecimento. [...] Mnemosyne é um objeto intempestivo, por se atrever, na era do positivismo e da história triunfal, a funcionar como um quebra-cabeça ou um jogo de cartas de tarô [...] Mnemosyne [Warburg] é, portanto, o objeto anacrônico por excelência, mergulha no imemorial (a astrologia babilônica das primeiras pranchas) para ressurgir no futuro (previsão, nas últimas pranchas, das irrupções fascistas e antissemitas). Houve quem dissesse que ele se situava a meia distância entre o Talmude e a Internet. Acima de tudo, ele cria uma configuração epistêmica nova - um conhecimento pela montagem que é próximo de Benjamin, bem como, sob certos aspectos, de Bataille e de Eisenstein”. (DIDI-HUBERMAN, 2013a, p. 406)

14 Uma prancha da montagem warburguiana explicada de forma exemplar por Georges Didi-Huberman (2012, p. 212): "Recordemos que, na última prancha do atlas Mnemosine, coabitam entre outras coisas uma obra de arte da pintura renascentista (A missa em Bolsena, pintada por Rafael no Vaticano), fotografias do acordo estabelecido em julho de 1929 por Mussolini com o papa Pio XI, 
bem como xilogravuras antissemitas (das Profanações de hóstia) contemporâneas dos grandes pogroms europeus de finais do século XV. O caso dessa reunião de imagens é tão emblemático como transtornante: uma simples montagem - à primeira vista gratuita, por força imaginativa, quase surrealista ao estilo das audácias surrealistas contemporâneas da revista Documents dirigida por Georges Bataille - produz a anamnese figurativa do laço entre um acontecimento político - religioso da modernidade (o acordo) e um dogma teológico-político de longa duração (a eucaristia); mas também entre um documento de cultura (Rafael no Vaticano ilustrando o dogma em questão) e um documento de barbárie (o Vaticano entrando complacentemente em relação com uma ditadura fascista). Ao fazer isso, a montagem de Warburg produz o clarão magistral de uma interpretação cultural e histórica, retrospectiva e prospectiva - essencialmente imaginativa - de todo o antissemitismo europeu”.

15 A dedicatória do livro de 1928: "Esta rua chama-se Rua Asja Lacis em homenagem àquela, que na qualidade de engenheiro, a rasgou dentro do autor". Asja Lacis foi uma diretora de teatro russa (letã) que participou da vanguarda soviética/alemã dos anos 1920/1930 e criou um teatro pedagógico proletário para crianças. Como diz Gagnebin (2017, p. 27): "A dedicatória para Asja em Rua de Mão Única, longe de ser uma declaração romântica, revela Asja como o engenheiro que "rasgou" uma nova rua no autor". Trata-se de uma alusão clara à violenta modernização das cidades europeias naquele momento e, claro, à violenta e arrebatadora paixão do autor pela "urbanista" Asja.

16 Benjamin descreveu em algumas cartas (sobretudo para Adorno) seu fascínio pelo livro de Aragon. Ele dizia não conseguir ler mais de duas ou três páginas do livro à noite na cama, pois seu coração batia muito forte. Também publicou um texto muito elogioso, em 1929, na Literarische Welt, sobre os surrealistas: "O surrealismo: o último instantâneo da inteligência europeia" (traduzido em português na coletânea Magia e técnica, arte e política, 1985).

17 As passagens, no século XIX, eram galerias comerciais de luxo, com piso em mármore e cobertas com estruturas de ferro e vidro, antes só usadas em importantes estações de trem ou galerias, como o Grand Palais. Elas apontavam para o futuro: da mercadoria, da arquitetura, da cidade. Quando Benjamin escreveu sobre as passagens, estas já tinham sido suplantadas pelas grandes lojas comerciais, como a famosa Galeries Lafayette (1896), e algumas passagens já estavam em vias de demolição.

18 Para Benjamin (1987b, p. 25), as passagens moldavam a própria imagem da modernidade, pressentindo o que ele chamou de "energias revolucionárias que transparecem no 'antiquado", no texto "O surrealismo, o último instantâneo da inteligência europeia”, no qual se lê: "no centro desse mundo de coisas está o mais onírico dos seus objetos, a própria cidade de Paris. Mas somente a revolta desvenda inteiramente o seu rosto surrealista. E nenhum rosto é tão surrealista 228 quanto o rosto verdadeiro de uma cidade”. 
19 Segundo Willi Bolle (2013), organizador da versão brasileira do livro das Passagens, o qual ele chamou de "verdadeira enciclopédia urbana", o livro reúne ao todo 4.232 fragmentos.

20 Dentre as diferentes citações do livro das Passagens, temos textos prioritariamente dos séculos XIX e XX, de vários autores e de diferentes campos do conhecimento, críticos, artistas, historiadores, literatos, poetas - com destaque para Baudelaire -, mas também comentadores de guias de turismo, de artigos de jornal ou de revistas, de anúncios de mobiliário urbano, entre outros. São autores de vários campos, mas também são várias formas de narração colocadas lado a lado. $\mathrm{O}$ trabalho das Passagens é uma enorme coleção de fragmentos heterogêneos, uma montagem fragmentária composta através de uma criteriosa seleção feita em arquivo bem maior, a própria Biblioteca Nacional, que reunia imensa quantidade dos milhares de livros e de outros documentos variados já escritos sobre a cidade de Paris.

21 Walter Benjamin, "Eduard Fuchs, coleccionista e historiador" In: Obras II. Madri, Abada, 2009, p. 68-108, tradução de Jorge Navarro Pérez. Ainda sobre a ideia da constelação e dos lampejos.

22 "Aquilo que experimentamos a cada dia com as imagens que nos rodeiam aparenta ser uma combinação de coisas novas e 'sobrevivências' vindas de muito longe na história da humanidade; assim como imagens de nosso passado mais profundo podem afetar nosso sonho da noite anterior. [...] Os artistas, filósofos e historiadores também existem para isso: para nos fazer entender que só vivemos nosso presente através dos movimentos conjugados das montagens de nossas memórias (gestos que realizamos em direção ao passado) e desejos (gestos que realizamos em direção ao futuro)”. (DIDI-HUBERMAN, 2013b)

23 Sobre a relação entre diferentes reformas urbanas e algumas narrativas errantes que também usaram a montagem como processo, ver nosso livro: Elogio aos errantes, publicado pela Edufba em 2012.

24 Sobre a relação entre o caleidoscópio e a modernidade, ver nosso texto "Caleidoscópio: processo da pesquisa”. (JACQUES, 2015)

25 "A história é objeto de uma construção cujo lugar não é o tempo homogêneo e vazio, mas um tempo saturado de 'agoras”". (BENJAMIN, 1994, p. 229)

26 A prática de montagens como forma de conhecimento ou de criação, de exposição de ideias ou de problematização de questões que emergem durante o próprio processo - que não é somente uma exposição ou ilustração de ideias já dadas, mas sim uma faísca de possibilidades não dadas - foi praticada sobretudo no período entre guerras por algumas vanguardas modernas - sobretudo pelos surrealistas na Europa e, no Brasil, pelos antropófagos - e, em particular, por uma constelação de artistas, escritores ou teóricos nos anos 1920 e 1930, 
como, além de Warburg e Benjamin, Sergei Eisenstein, no cinema; Bertold Brecht, no teatro; ou Georges Bataille, na literatura; entre vários outros. No Brasil, Oswald de Andrade, na literatura; Tarsila do Amaral, na pintura; ou Flávio de Carvalho, na arquitetura e outras artes, para citar alguns dos mais importantes do movimento antropófago brasileiro.

27 Essa vertente - de intelectuais modernos, herdeiros, sobretudo, do romantismo alemão, que recusam as ilusões do progresso e buscaram descontruir essa ideologia moderna do progresso técnico - industrial, não em nome da sua conservação ou de um simples retorno ao passado, mas sim de uma revolução -, por alguns é vista como neorromântica utópica, mas, ao contrário, traz uma concepção da história bastante interessante, não buscando um retorno a um passado ideal, mas sim algo bem mais complexo: um desvio crítico pelo passado em direção a um outro futuro. Dessa tradição, fizeram parte vários "judeus heterodoxos”, para falar como Michael Löwy - estudioso dessa rica vertente que mistura romantismo, surrealismo, messianismo e utopia -, que, além de Walter Benjamin, reuniu vários nomes de judeus de "cultura" alemã, que já intuíam a eminente catástrofe do nazismo, como Hannah Arendt, Franz Rosenzweig, Ernst Bloch, Georg Lukács, Gerschom Scholem, Martin Buber, entre outros. Para Benjamin, a utopia não era vista como um resultado do progresso, mas sim de uma visão de mundo (weltanschaung). Trata-se de uma forma de pensar, uma (auto)crítica da modernidade, um tipo de interrupção necessária de uma "evolução histórica" que conduzia diretamente para uma catástrofe. Essa vasta corrente de crítica moderna aos excessos da própria modernidade, partindo de uma tradição romântica revolucionária alemã, se ressentia do chamado "desencantamento do mundo" (entzauberung der welt) e buscava seu possível reencantamento dentro da própria modernidade. Um trabalho mais aprofundado sobre essa hipótese está em preparação - “Outros modernos”, tese para progressão para categoria de professor titular em andamento, cujo título ainda é provisório.

28 Conferência de Nicole Loraux em São Paulo, no ciclo de conferências "Tempo e história - Caminhos da memória, trilhas do futuro", coordenado pela Assessoria de Projetos Especiais da Secretaria Municipal de Cultura de São Paulo, publicado em Tempo e história, em 1992. Depois, o texto foi publicado em nova versão, em francês, com o título: "Eloge de l'anachronisme en histoire".

29 Essa passagem de Agamben (2009, original em italiano de 2008) se assemelha muito ao que Rancière (2011, original em francês de 1996) escreve, diferenciando linhas de temporalidade de tempos: "Há história à medida que os homens não se 'assemelham' ao seu tempo, com a linha de temporalidade que os coloca em seus lugares impondo-lhes fazer do seu tempo este ou aquele 'emprego'. Mas essa ruptura mesma só é possível pela possibilidade de conectar essa linha de temporalidade com outras, pela multiplicidade de linhas de temporalidade 230 presentes em 'um' tempo”. 
30 "Não existe anacronismo. Mas existem modos de conexão que podemos chamar positivamente de anacronias: acontecimentos, noções, significações que tomam o tempo de frente para trás, que fazem circular sentido de uma maneira que escapa a toda contemporaneidade, a toda identidade do tempo com 'ele mesmo'. Uma anacronia é um palavra, um acontecimento, uma sequência significante saídos do 'seu' tempo, dotados da capacidade de definir direcionamentos temporais inéditos, de garantir o salto ou a conexão de uma linha de temporalidade com outra. E é através desses direcionamentos, desses saltos, dessas conexões que existe um poder de 'fazer' a história. A multiplicidade das linhas de temporalidades, dos sentidos mesmo de tempo incluídos em um 'mesmo' tempo, é a condição do agir histórico. Levá-lo efetivamente em conta deveria ser o ponto de partida da ciência histórica, menos preocupada com sua respeitabilidade científica e mais preocupada com o que quer dizer "história”. (RANCIÉRE 2011, p. 49)

31 "[...] worin das Gewesene mit dem Jetzt blitzhaft zu einer Kostellation zusammentritt" (Das passagen-Werk, Gesammelte Schiften, 1982). A tradução brasileira da frase completa, que usamos em tradução livre a partir das versões em francês e alemão, troca a expressão "como um relâmpago" (blitzhaft, dans un éclair) por "lampejo": "Não é que o passado lança sua luz sobre o presente ou que o presente lança sua luz sobre o passado; mas a imagem é aquilo em que o ocorrido encontra o agora num lampejo, formando uma constelação”. 


\section{REFERẼNCI IS}

ARENDT, H. Walter Benjamin 1842-1940. Paris: Editions Allia, 2007.

AGAMBEM, G. Aby Warburg e a ciência sem nome. Revista ArteĖEnsaios, Rio de Janeiro, n. 19 , p. 132-143, 2009.

AGAMBEM, G. O que é o contemporâneo? In: AGAMBEM, G. O que é o contemporâneo? e outros ensaios. Tradução de Vinícius Nicastro Honesko. Chapecó: Argos, 2009. p. 55-73.

BENJAMIN, W. A imagem de Proust. In: BENJAMIN, W. Magia e técnica, arte e política: ensaios sobre literatura e história da cultura. Tradução de Sergio Paulo Rouanet. 3. ed. São Paulo: Brasiliense, 1987a. p. 36-49. (Obras Escolhidas, v. 1).

BENJAMIN, W. Magia e técnica, arte e política: ensaios sobre literatura e história da cultura. Tradução Paulo Sérgio Rouanet. São Paulo: Brasiliense, 1994. (Obras escolhidas, v. 1).

BENJAMIN, W. Paris, capital do século XIX. In: KOTHE, F. R. (Org.). Walter Benjamin. São Paulo: Ática, 1985. p. 30-43.

BENJAMIN, W. Passagens. Tradução de Irene Aron; Cleonice Paes Barreto Mourão. Belo Horizonte: Editora UFMG, 2009.

BENJAMIN, W. Rua de mão única. São Paulo: Brasiliense, 1987.

(Obras escolhidas, v. 2).

BENJAMIN, W. O surrealismo: o último instantâneo da inteligência europeia. In: BENJAMIN, W. Magia e técnica, arte e política: ensaios sobre literatura e história da cultura. Tradução de Sergio Paulo Rouanet. 3. ed. São Paulo: Brasiliense, 1987b. p. 21-35. (Obras Escolhidas, v. 1).

BOLLE, W. Les Passages - livre, archives ou encyclopédie magique? Cahier de l'Herne, Paris, p. 245-252, 2013.

DIDI-HUBERMAN, G. Atlas ou le gai savoir inquiet: L'œil de l'histoire 3. Paris: Les éditions de Minuit, 2011a.

232 DIDI-HUBERMAN, G. Devant le temps. Paris: Les éditions de minuit, 2000. 
DIDI-HUBERMAN, G. Diante do tempo: história da arte e anacronismos das imagens. Tradução de Vera Casa Nova; Márcia Arbex. Belo Horizonte: Editora UFMG, 2015. (Coleção Humanitas).

DIDI-HUBERMAN, G. A imagem sobrevivente: história da arte e tempo dos fantasmas segundo Aby Warburg. Tradução de Vera Ribeiro. Rio de Janeiro: Contraponto, 2013a. (Coleção Artefissil).

DIDI-HUBERMAN, G. História de fantasmas para gente grande. Rio de Janeiro: MAR, 2013b. Folheto distribuído da exposição Atlas.

DIDI-HUBERMAN, G. L'image survivant: histoire de l'art et temps de fantômes selon Aby Warburg. Paris: Les Éditions de Minuit, 2002.

DIDI-HUBERMAN, G. Quando as imagens tocam o real. Pós, Belo Horizonte, v. 2, n. 4, p. 204-219, nov. 2012.

DIDI-HUBERMAN, G. Quand les images prennent position: L'œil de l'histoire, 1. Paris: Les Éditions de Minuit, 2009.

DIDI-HUBERMAN, G. Remontée, remontage (du temps). Revue Étincelle, Paris, nov. 2007.

DIDI-HUBERMAN, G. Sobrevivência dos vaga-lumes. Tradução de Vera Casa Nova; Márcia Arbex. Belo Horizonte: Editora UFMG, 2011 b.

GAGNEBIN, J. M. Canteiro de obra. In: JACQUES, P. B.; BRITTO, F. D. Corpocidade: gestos urbanos. Salvador: EDUFBA, 2017.

GAGNEBIN, J. M. Entrevista. Redobra, Salvador, n. 15, p. 13-17, 2016.

GAGNEBIN, J. M. História e narração em Walter Benjamin. 2. ed. São Paulo: Perspectiva, 1999. (Coleção Estudos).

GINZBURG, C. de A. Warburg a E. H. Gombrich. In: GINZBURG, C. de A. Mitos, emblemas, sinais. São Paulo: Cia das letras, 1989. p. 41-93.

JACQUES, P. B. Elogio aos errantes. Salvador: EDUFBA, 2012.

JACQUES, P. B. Montagem urbana. In: JACQUES, P. B.; BRITTO, F. D.; DRUMMOND, W. (Org.). Memória, narração, história: experiências metodológicas para compreensão da complexidade da cidade contemporânea (Tomo IV). Salvador: EDUFBA, 2015. p. 47-94. 
JACQUES, P. B. et al. Temporalidades. In: JACQUES, P. B.; BRITTO, F. D. Corpocidade: gestos urbanos. Salvador: EDUFBA, 2017. p. 295-349.

JACQUES, P. B.; BRITTO, F. D.; DRUMMOND, W. (Org.). Experiências metodológicas para compreensão da complexidade da cidade contemporânea. Salvador: EDUFBA, 2015. v. 4. (Coleção PRONEM).

LORAUX, N. Elogio do Anacronismo. In: NOVAES, A. (Org.). Tempo e história. São Paulo: Companhia das Letras: Secretaria Municipal de Cultura, 1992. p. 57-70.

MANN, N.; GUIDI, B. C. Photographs at the frontier: Aby Warburg in America 1895-1896. Londres: Merrell Holberton, 1998.

PROUST, M. Em busca do tempo perdido. Tradução de Mário Quintana. 3. ed. São Paulo: Globo, 2006.

RANCIÉRE, J. O conceito de anacronismo e a verdade do historiador. In: SALOMON, M. (Org.). História, verdade e tempo. Chapecó: Argos Editora, 2011. p. 21-49.

TEITELBAUM, M. (Org.). Montage and Modern Life 1919-1942. Cambridge: MIT press, 1992.

WAIZBORT, L. Apresentação. In: WARBURG, A. Histórias de fantasma para gente grande. São Paulo: Companhia das Letras, 2015. p. 7-22.

WARBURG, A. Histórias de fantasma para gente grande. Tradução de Lenin Bicudo Bárbara. São Paulo: Companhia das Letras, 2015a.

WARBURG, A. Introdução à Mnemosine. In: WARBURG, A. História de fantasma para gente grande. São Paulo: Companhia das Letras, 2015b. p. 363-374.

WARBURG, A. Mnemosyne. Revista ArteÉEnsaios, Rio de Janeiro, n. 19, p. 125-131, 2009.

WITTE, B. Walter Benjamin, uma biografia. Tradução de Romero Freitas. Belo Horizonte: Autêntica, 2017. 